\title{
Association of C-reactive Protein with Fasting blood glucose in Newly Diagnosed Type 2 Diabetes Mellitus Patients
}

\author{
Md. Matiur Rahman1, Abu Hena Mostafa Kamal2, \\ Forhadul Hoque Mollah ${ }^{3}$, Md. Golam Hafiz 4 , M. Iqbal Arslan5
}

\begin{abstract}
Type 2 Diabetes Mellitus is associated with a marked increase in atherosclerotic micro and macrovascular diseases involving cardiac, cerebral and peripheral large vessels. Sub clinical systemic inflammatory marker CRP may positively be associated with atherosclerotic risk of future coronary artery disease, cerebrovascular disease or peripheral arterial disease. This study was conducted to see the association between serum C-reactive protein and fasting blood glucose in Type 2 Diabetes Mellitus patients. It was a case control study carried out in the Department of Biochemistry, BSMMU during the period of July, 2008 to June, 2009. Total 80 subjects were included in this study with age range from 30 to 60 years of both sexes. Among them 40 were cases of Type 2 Diabetes Mellitus patients having fasting blood glucose level ? $7.0 \mathrm{mmol} / \mathrm{L}$ without micro and macrovascular complications and 40 were age matched healthy control having fasting blood glucose $<6.0 \mathrm{mmol} / \mathrm{L}$. Venous blood was collected and fasting blood glucose and serum C-reactive protein were estimated by Spectrophotometrically. Unpaired ' $t$ ' test and Pearson correlation coefficient tests were done as the tests of significance. In this study serum $C$ - reactive protein level was significantly $(p<0.05)$ higher in Type 2 Diabetes Mellitus patients as compared to healthy control subjects. Highly significant $(p<0.001)$ positive correlation was found between serum $C$-reactive protein and fasting blood glucose level of Type 2 Diabetes Mellitus patients. Therefore, it was assumed from this study that chronic high serum C- reactive protein level may be an indicator of risk for development of atherosclerosis.
\end{abstract}

Key words: Type 2 Diabetes Mellitus, C- reactive protein, Atherosclerosis.

\section{Introduction}

Type 2 Diabetes mellitus (DM) is a complex condition, combination of resistance to the actions of insulin in liver and muscle together with impaired pancreatic $\beta$-cell function leading to 'relative' insulin deficiency ${ }^{1}$. Type $2 \mathrm{DM}$ is affecting more than $3 \%$ of all adults and more than $10 \%$ of older than 65 years, making it 8 to 10 times more common than Type 1 diabetes and accounts for over $90 \%$ of diabetes cases worldwide 2 . The prevalence of Type 2 Diabetes Mellitus in Bangladesh is $4.3 \%^{3}$. Type 2 DM is associated with marked increase in atherosclerotic macrovascular diseases involving cardiac, cerebral and peripheral large vessels ${ }^{4}$. The patients with type $2 \mathrm{DM}$ and no prior history of coronary heart disease have an equivalent risk of developing a myocardial infarction as non-diabetics with a prior myocardial infarction 5 . Type $2 \mathrm{DM}$ is associated with two to four fold excess risk of coronary heart disease, a five fold increase in risk of fatal stroke and a significantly increased risk of atherosclerosis-induced gangrene of lower limbs as compared to non-diabetic individuals. The increased atherosclerosis risk is attributed to the high prevalence of several predisposing factors like obesity, hypertension, insulin resistance and dyslipidemia in these patients 6 . More than 3 out of 4 diabetic patients die of causes related to atherosclerosis, in most cases because of coronary artery disease 7 . Type $2 \mathrm{DM}$ is now recognized as an inflammatory condition associated with insulin resistance and abnormal endothelial vascular

1. Dr. Md. Matiur Rahman, Department of Biochemistry Bangabandhu Sheikh Mujib Medical University, Dhaka, Bangladesh.

2. Dr. Abu Hena Mostafa Kamal, Department of Biochemistry, Bangabandhu Sheikh Mujib Medical University, Dhaka, Bangladesh.

3. Dr. Forhadul Hoque Mollah, Department of Biochemistry, Bangabandhu Sheikh Mujib Medical University, Dhaka, Bangladesh.

4. Dr. Md. Golam Hafiz, Department of Pediatric Hematology Oncology, Bangabandhu Sheikh Mujib Medical University, Dhaka, Bangladesh.

5. Professor M. Iqbal Arslan, Department of Biochemistry, Bangabandhu Sheikh Mujib Medical University, Dhaka, Bangladesh. 
reactivity. It is an increasingly prevalent risk for atherosclerotic micro and macrovascular diseases 8 . The pathogenesis of atherosclerosis in diabetes is complex, but serum lipids are frequently abnormal and likely contribute to the risk of coronary artery disease $^{9}$.

Diabetes is not only a well known risk factor for atherosclerosis but is also associated with increased levels of sensitive markers of sub clinical systemic inflammation like $\mathrm{C}$-reactive protein (CRP) ${ }^{10}$. CRP is an acute phase reactant protein produced in the liver and important in the non specific host defense against inflammation. Chronically increased serum CRP concentrations are positively associated with a risk of future coronary artery disease, cerebrovascular disease or peripheral arterial disease. Possible mechanism of atherosclerosis by CRP to enhance expression of local endothelial cell surface adhesion molecules, monocyte chemoattractant protein-1, endpthelin-1, and endothelial plasminogen activator inhibitor-1; reduce nitric oxide bioactivity; increase the induction of tissue factors in monocytes and LDL-C uptake by macrophages and co-localize with compliment membrane attack complex within the atherosclerotic letions ${ }^{11}$. There is a strong and independent association between even slightly elevated concentrations of CRP and cardiovascular events in initially healthy subjects and in patients with manifested atherosclerosis ${ }^{12}$. CRP is a more powerful predictor of cardiovascular risk than traditional risk factors such as LDL-C13. The impact of LDL-C on the risk of CVD is augmented by the presence of an inflammatory marker such as CRP. The combination of elevation of both has more ominous implications than elevation of either alone. The impact of a combination of elevated LDL-C accompanied by increased serum CRP is also an acute-phase reactant as well as a thrombogenic risk factor ${ }^{14}$. The systemic inflammation among people with impaired insulin-mediated glucose homeostasis results in atherosclerosis. CRP was elevated in clinical and sub clinical atherosclerosis, possibly as a result of the atherosclerosis process ${ }^{15}$. In newly diagnosed or established Type 2 DM patients serum CRP level elevated in compared with non diabetic subjects 16 .

About more than 3 out of 4 individuals with diabetes die of atherosclerosis and its complications. The high level of serum CRP possibly predispose to development of atherosclerotic diseases. The present case control study was aimed to explore the association between serum CRP and fasting blood glucose in Type $2 \mathrm{DM}$ patients.

\section{Materials \& methods}

The present case control study was carried out in the department of Biochemistry, Bangabandhu Sheikh Mujib Medical University (BSMMU), Dhaka, Bangladesh from July 2008 to June 2009. Total number of 80 subjects was included in this study with age range from 30 to 60 years of both sexes. Among them 40 were cases of Type 2 Diabetes Mellitus patients having fasting blood glucose level $\geqslant 7.0 \mathrm{mmol} / \mathrm{L}$. and 40 were age matched healthy control having fasting blood glucose $<6.0$ $\mathrm{mmol} / \mathrm{L}$. All the cases of Type 2 Diabetes Mellitus patients without micro and macrovascular complications were selected from the Out Patient Department of BIRDEM, Dhaka and BSMMU, Dhaka. All the healthy control subjects were selected from persons attending with Diabetic patients. All the study subjects were enrolled by convenient and purposive sampling technique. The objectives and benefits of the study were explained to all the study subjects to ensure their voluntary participation and informed written consent was taken from each subject prior to the study. Five (5) $\mathrm{ml}$ of venous blood was collected from the anticubital vein with all aseptic preqution. Blood was centrifuged at 3000 rmp and serum was separated. Fasting blood glucose was measured as early as possible by enzymatic glucose oxidase method by Spectrophotometer ${ }^{18}$. Serum CRP was measured by Spectrophotometrically by Dade Behring ${ }^{19}$. All the tests were done in the Department of Biochemistry and the Department of Microbiology \& Immunology, BSMMU. Data were expressed as Mean \pm SD. Unpaired ' $t$ ' test and Pearson correlation coefficient test were done as the tests of significance. The statistical analysis was done by using SPSS programme version 12. $p$ value $<0.05$ was considered as level of significant.

\section{Results}

Mean \pm SD concentrations of fasting blood glucose in cases and controls were $11.36 \pm 4.39$ and $4.99 \pm$ $0.96 \mathrm{mmol} / \mathrm{L}$ respectively. Fasting blood glucose level was significantly $(p<0.001)$ higher in cases as compared to healthy control subjects. The concentrations of serum CRP in Type 2 Diabetes patients and healthy controls were $7.27 \pm 5.02$ and $5.40 \pm 0.49 \mathrm{mg} / \mathrm{L}$ respectively. In Type 2 Diabetes Mellitus patients serum CRP level was significantly $(p<0.05)$ higher than healthy controls (table-l). Correlation analysis showed highly significant $(p<$ $0.001)$ positive correlation between serum CRP and fasting blood glucose in Type 2 DM patients (figure-1). 


\section{Table-I}

Distribution and comparison of Fasting blood glucose and Serum CRP in study subjects.

\begin{tabular}{lcccc}
$\begin{array}{l}\text { Biochemical } \\
\text { Parameter }\end{array}$ & Case $(n=40)$ & Control $(n=40)$ & 'T'Value ' $p$ ' Value \\
\hline $\begin{array}{l}\text { Fasting blood glucose } \\
\text { mmol/L } \\
\text { (Mean } \pm \text { SD) }\end{array}$ & $11.36 \pm 4.39$ & $4.99 \pm 0.96$ & 8.98 & 0.0001 \\
\hline $\begin{array}{l}\text { Serum CRP } \\
\text { mg/L } \\
(\text { Mean } \pm \text { SD) }\end{array}$ & $7.27 \pm 5.02$ & $5.40 \pm 0.49$ & 2.34 & 0.022 \\
\hline
\end{tabular}

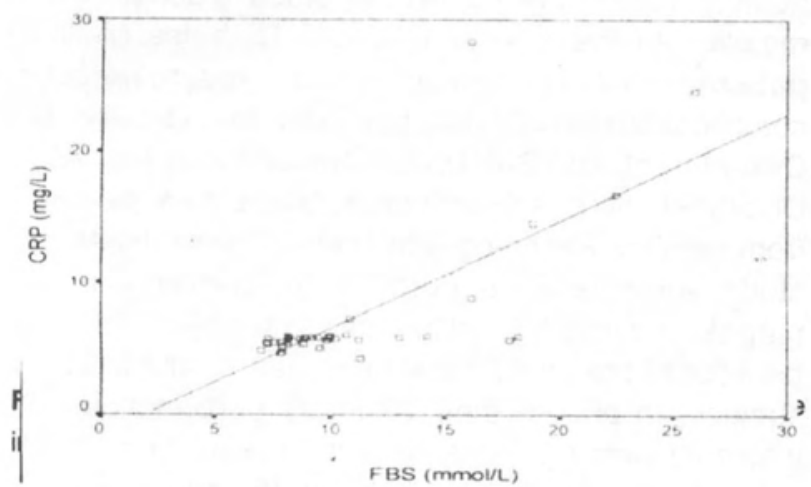

\section{Discussion}

Type $2 \mathrm{DM}$ is responsible for the development of atherosclerotic diseases like coronary artery disease, cerebrovascular disease and peripheral artery disease. Serum CRP also an immerging risk factor for development of atherosclerosis. In our study the serum CRP level was significantly higher in Type 2 DM patients in comparison to healthy control subjects. These findings were consistent with the study by John ${ }^{16}$. In the present study highly significant positive correlation was found between serum CRP and fastig blood glucose in Type 2 DM patients. Similar findings were reported in a study by other ${ }^{15}$. Type $2 \mathrm{DM}$ is now recognized as an inflammatory condition associated with insulin resistance and abnormal endothelial vascular reactivity. It is an increasingly prevalent risk for atherosclerotic micro and macrovascular diseases 8 . There is a strong and independent association between even slightly elevated concentrations of CRP and cardiovascular events in initially healthy subjects and in patients with manifest atherosclerosis 12 .

In the present study serum CRP was significantly high in Type 2 Diabetes Mellitus patients as compared to healthy control subjects. Highly significant positive correlation was found between serum CRP and fasting blood glucose in Type 2 Diabetes Mellitus patients. Therefore, it is assumed from this study that high serum CRP level is an indicator of risk for development of atherosclerosis. A large scale prospective base line study should be carried out to establish the serum CRP is an independent risk for atherosclerosis.

\section{References}

1. Fier BM, Fisher M. 'Diabetes Mellitus' in Davidson's Principles \& Practice of Medicine, 20th ed, Nicholas A. Boon, Nicki R. Colledge, Brian R. Walker, John A. A. Hunter. Churchill Livingstone Elsevier, 2006; 805848.

2. Gaster B, Hirsch B. The effects of Glycemic control on complications in Type 2 Diabetes. Arch Intern Med. 1998; 158(2) 134-140.

3. Sayeed MA, Mahtab H, Khanam PK, Latif ZF, Ali SMK, and Banu $A$ et al. Diabetes and Impaired fasting Glycemia in a Rural Population of Bangladesh. Diabetes Care. 2003; 26: 1034-1039.

4. David B, Sacks MB, Ch B. 'Diabetes mellitus' in Tietz Texbook of Clinical Chemistry and Molecular Biology, 4th ed, Carl A. Burtis, Edward R. Ashwood, David E. Burns, Elsevier, 2006; 853-863.

5. Keoing W. C-reactive protein and cardiovascular risk: an update on what is going on cardiology. Nephrol Dial Transplant. 2003; 18: 1039-1041.

6. Udawat $\mathrm{H}, \mathrm{Goyal}$ RK. Dyslipidemia in type 2 diabetes mellitus. Int J Diabetes \& Metabolism. 2000; 8: 101111

7. Haffner SM, Ronnemaa LST, Pyorala K, Laakso M. Mortality from coronary heart disease in subjects with type 2 diabetes and in nondiabetic subjects with and without prior myocardial infarction. $\mathrm{N}$ Engl J Med. 1998; 339: 229-34.

8. Lin J, Frank BH, Eric BR, Nader R, Gary CC. The Association of Serum Lipids and Inflammatory Biomarkers with Renal Function in Men with Type 2 Diabetes Mellitus. Kidney Int. 2006; 69(2): 336-342.

9. Cook CB, Erdman DM, Ryan PGJ, Greenlund PKJ, Giles WH, Gallina DL et al. The Pattern of Dyslipidemia Among Urban African-Americans With Type 2 Diabetes. Diabetic care. 2006; 23(3).

10. Gustavasson CG, Agardh CD. Markers of inflammation in patients with coronary artery disease are also associated with glycosylated haemoglobin A1c within the normal range. European Heart Journal. 2004; 25(23): 120-124.

11. Rifai N, Warnick R. 'Other Cardiac Risk factors', in Tietz Texbook of Clinical Chemistry and Molecular Biology. 4th edition, Carl A. Burtis, Edward R. Ashwood, David E. Burns, Elsevier, 2006; 962-982.

12. Chait A, Han CY, Oram JF, Heineck JW. Thematic review series the Immune System and Atherosclerosis Lipoprotein associated inflammatory proteins markers of cardiovascular disease. Journal of Lipid Research. 2005; 46: 389-403. 
13. Kannel WB. Overview of Hemostatic Factors Involved in Atherosclerotic Cardiovascular Disease. Lipids. 2005; 40 (12): 1215-1221.

14. King DE, Mainous AG, Buchanan TA, Pearson WS. C-Reactive Protein and Glycemic Control in Adults With Diabetes. Diabetes care . 2003; 26: 1535-1539.

15. Wu T, Dorn JP, Donahue RP, Sempos CT, Trevisan M. Association of C-Reactive proteion with Fasting Insulin, Glucose and Glycosylated Hemoglobin The Third Natioonnal Health and Nutrition Examination surveys. American Journal of Epidemiology. 2002; 155(1): 67-71.

16. John C. Inflammation and Activated Innate Immunity in the Pathogenesis of Type 2 Diabetes. Diabetes Care. 2004; 27: 813-823.

17. Burtis CA, Ashwood ER. Tietz Fundamentals of clinical Chemistry, 4th ed, W.B. Saunders Company, Philadelphia, PA 2001: 444-445.

18. Kushner I, Rzewnicki DL. The acute phase response: general aspects. Bailliers Clin Rheumatol. 1994; 8: 513-30. 